\title{
Defining the Frontiers of Bioengineering Education at Illinois and Beyond
}

\author{
Dr. Jennifer R Amos, University of Illinois, Urbana-Champaign
}

Dr Amos joined the Bioengineering Department at the University of Illinois in 2009 and is currently a Teaching Associate Professor in Bioengineering and an Adjunct Associate Professor in Educational Psychology. She received her B.S. in Chemical Engineering at Texas Tech and Ph.D. in Chemical Engineering from University of South Carolina. She completed a Fulbright Program at Ecole Centrale de Lille in France to benchmark and help create a new hybrid masters program combining medicine and engineering and also has led multiple curricular initiative in Bioengineering and the College of Engineering on several NSF funded projects.

\section{Prof. Rashid Bashir, University of Illinois, Urbana-Champaign}

Rashid Bashir completed his Ph.D. from Purdue University in Oct. 1992. From Oct. 1992 to Oct. 1998, he worked at National Semiconductor in the Analog/Mixed Signal Process Technology Development Group, where he was promoted to Sr. Engineering Manager. At National Semiconductor, he led the development and commercialization of 4 analog semiconductor process technologies. He joined Purdue University in Oct. 1998 as an Assistant Professor and was later promoted to Professor of Electrical and Computer Engineering and a Courtesy Professor of Biomedical Engineering and Mechanical Engineering. Since Oct. 2007, he joined the University of Illinois at Urbana-Champaign and was the Abel Bliss Professor of Engineering, and Professor of Electrical and Computer Engineering \& Bioengineering. He was the Director of the Micro and Nanotechnology Laboratory (mntl.illinois.edu), a campus-wide clean room facility from Oct 2007 to Aug 2013 and the Co-Director of the campus-wide Center for Nanoscale Science and Technology (www.cnst.illinois.edu), a "collaboratory" aimed at facilitating center grants and large initiatives around campus in the area of nanotechnology. Since Aug 2013, he has been the head of the Bioengineering Department. In Oct 2016, he was named the Grainger Distinguished Chair in Engineering. From Jan 2017, he is the Interim Vice Dean of the new Carle-Illinois 'Engineering Based' College of Medicine at UIUC. He has authored or co-authored over 200 journal papers, over 200 conference papers and conference abstracts, over 100 invited talks, and has been granted 42 patents. He is a fellow of 6 international professional societies (IEEE, AIMBE, AAAS, APS, IAMBE, and BMES). His research interests include bionanotechnology, BioMEMS, lab on a chip, interfacing of biology and engineering from the molecular to the tissue scale, and applications of semiconductor fabrication to biomedical engineering, all applied to solving biomedical problems. Prof. Bashir's key technical contributions and achievements lie in the area of BioMEMS and biomedical nanotechnology, especially in the use of electrical- or mechanical-based label-free methods for detection of biological entities on a chip. In addition, he has also made key contributions to 3-D fabrication methods that can be used for tissue engineering and development of cellular systems. He has been involved in 3 startups that have licensed his technologies (BioVitesse, Inc., Daktari Diagnostics, and most recently Prenosis, Inc.).

\section{Dr. Kelly J Cross, University of Illinois, Urbana-Champaign}

Dr. Cross completed her doctoral program in the Engineering Education department at Virginia Tech in 2015 and worked as a post-doctoral researcher with the Illinois Foundry for Innovation in Engineering Education at the University of Illinois at Urbana-Champaign. At UIUC she has collaborated with multiple teams of engineering faculty on implementing and assessing instructional innovation. Dr. Cross is currently a Research Scientist in the Department of Bioengineering working to redesign the curriculum through the NSF funded Revolutionizing Engineering Departments (RED) grant. She is a member of the ASEE Leadership Virtual Community of Practice that organizes and facilitates Safe Zone Training workshops. Dr. Cross has conducted multiple workshops on managing personal bias in STEM, both online and in-person. Dr. Cross' scholarship investigated student teams in engineering, faculty communities of practice, and the intersectionality of multiple identity dimensions. Her research interests include diversity and inclusion in STEM, teamwork and communication skills, assessment, and identity construction.

Dr. Geoffrey L Herman, University of Illinois, Urbana-Champaign 
Dr. Geoffrey L. Herman is a teaching assistant professor with the Deprartment of Computer Science at the University of Illinois at Urbana-Champaign. He also has a courtesy appointment as a research assistant professor with the Department of Curriculum \& Instruction. He earned his Ph.D. in Electrical and Computer Engineering from the University of Illinois at Urbana-Champaign as a Mavis Future Faculty Fellow and conducted postdoctoral research with Ruth Streveler in the School of Engineering Education at Purdue University. His research interests include creating systems for sustainable improvement in engineering education, conceptual change and development in engineering students, and change in faculty beliefs about teaching and learning. He serves as the Publications Chair for the ASEE Educational Research and Methods Division.

\section{Prof. Jeffrey Loewenstein, University of Illinois, Urbana-Champaign Dr. Marcia Pool, University of Illinois, Urbana-Champaign}

Dr. Marcia Pool is a Lecturer in bioengineering at the University of Illinois at Urbana-Champaign. In her career, Marcia has been active in improving undergraduate education through developing problem-based laboratories to enhance experimental design skills; developing a preliminary design course focused on problem identification and market space (based on an industry partner's protocol); and mentoring and guiding student teams through the senior design capstone course and a translational course following senior design. To promote biomedical/bioengineering, Marcia works with Women in Engineering to offer outreach activities and is engaged at the national level as Executive Director of the biomedical engineering honor society, Alpha Eta Mu Beta.

\section{Ms. Dorothy Silverman, University of Illinois Urbana-Champaign}




\title{
Defining the Frontiers of Bioengineering Education at Illinois and Beyond
}

\begin{abstract}
The Department of Bioengineering at the University of Illinois is revolutionizing its curriculum by increasing its focus on teaching students about the societal needs that necessitate bioengineering solutions. In this paper, we provide an overview of the goals of our revolution and the process by which we will create this change. We provide examples of how we are centering our curriculum around addressing society needs through clinical immersion experiences and disease-centered learning tracks.
\end{abstract}

\section{Introduction}

"No solution without a need." The Department of Bioengineering at the University of Illinois is using this simple message to revolutionize what it means to teach our students.

Engineers design and create tools, products, and systems that change society and improve the lives of people. The most impactful products are ones that address profound societal and personal needs. We speak of engineering as grand challenges because engineering is essential for addressing urgent societal issues such as combatting global climate change, ensuring a secure food supply, or providing sustainable and effective medical care. For our engineering students to be effective at addressing the societal needs posed by these grand challenges, our students must understand the "needs" that require engineering solutions as well as the science and technologies that make engineering effective.

While traditional engineering curricula are organized around scientific principles (e.g., signals and systems) or technologies (e.g., imaging), our new curriculum will be organized around the physician and patient needs (e.g, curing cancer or sustainable access to healthcare) that necessitate the science and technology. These curriculum revisions are being supported through the National Science Foundation's Revolutionizing Engineering Departments (RED) program [EEC 1623141].

In this paper, we will describe the threats (needs) that are driving our revolution and then describe the objectives that we are undertaking to address those threats. We will particularly focus on describing our preliminary efforts toward creating the clinical immersion experiences for firstyear students that will satisfy the first two objectives.

\section{Background}

Catalyzed by the Grinter Report ${ }^{1}$, engineering education was previously revolutionized by aligning its practice and education with science ${ }^{2}$. This alignment created a social-technical duality in engineering where the technical skills were elevated, social skills were relegated ${ }^{3-5}$. In response, calls have recently risen for holistic training of engineering students who understand the societal needs and the societal implications of their practice ${ }^{5-8}$. The need to create holistic engineers is particularly important in bioengineering, where the technologies and systems we develop directly impact people, diseases, pathologies, and challenges that they experience on a 
daily basis. Therefore, bioengineering education needs to more deeply align with the practice of modern medicine that care for both human needs.

Inequities driven by rising costs of healthcare, the increased role of technology in medicine, and ethical dilemmas driven by increases in population and age-related diseases are a few of the many complex and ill-defined problems in healthcare ${ }^{9-11}$. Both engineers and healthcare providers must precede and drive science by translating social needs into technical problems to solve urgent social needs ${ }^{5,8,12,13}$. We need to determine how to provide "higher quality healthcare to more people at lower cost" and train bioengineering leaders of tomorrow to drive "Moore's law for health care ${ }^{14}$."

\section{Change Theory}

Since a core goal of our effort is to execute a significant change to our department's curriculum and norms, we briefly discuss our theory of change to explain how we plan to redefine our curriculum. Organizational research amply demonstrates that "how changes are made and communicated" matters more than "what changes are made ${ }^{15}$." Members of a community undergoing change are keenly attuned to just treatment ${ }^{16}$. To foster a sense of just practices during a change

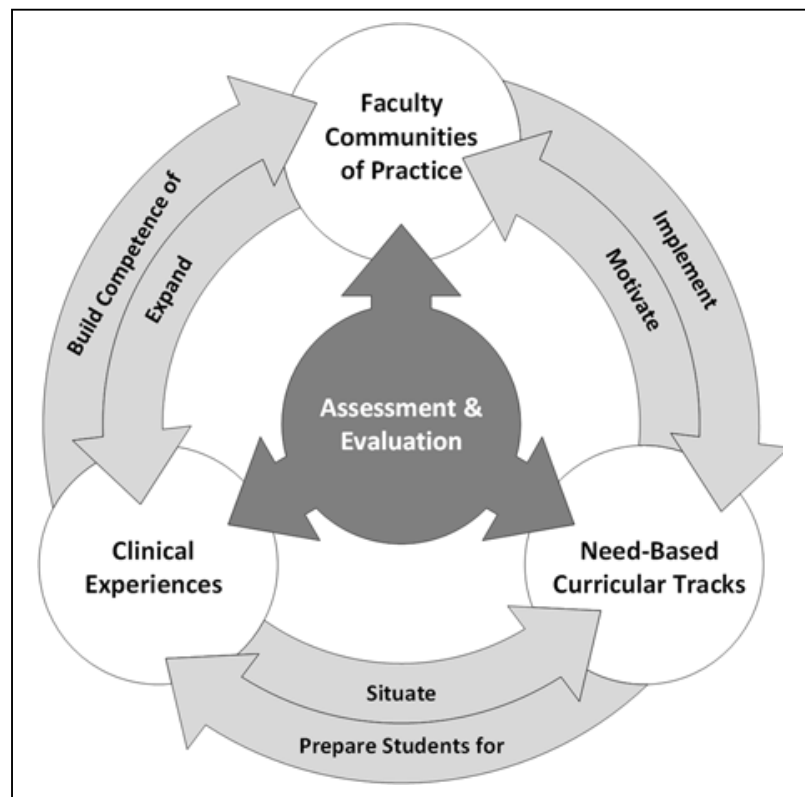

Figure 1: Symbiosis between project objectives. initiative, administrators must engage stakeholders (faculty and students) in the process of change. Specifically, they must (1) communicate clearly, completely, consistently, and repeatedly about the threats that necessitate change, (2) involve stakeholders to help shape solutions so they fit stakeholder interests, and (3) use principled means to provide and distribute resources to facilitate the adoption of new practices ${ }^{17}$. Changing the entire department's model for training students will require more than just compliance to be successful. It will require commitment and willing engagement.

Critically, motivating the change among our faculty requires that we understand and frame the change we wish to see from the perspective of the threats that our department and our faculty are experiencing. Through open communication and identification of threats and opportunities, we hope that other institutions facing similar threats will be able to benefit from our change process.

\section{Key Threats that Motivate our Revolution}

We have identified four critical threats facing the students, staff, and faculty of our department that necessitate change. We begin by describing three threats that are more general to many bioengineering or engineering departments, but also describe one particular local threat that has created particular urgency for creating change in our department.

1. The design of innovative technologies that can aid doctors and patients is pointless if these technologies are not actually used by those doctors and patients. Increasing the 
uptake of biotechnologies requires an understanding of doctors' and patients' needs and matching product designs to those needs. Traditional lecture or classroom-based pedagogies do not afford students with opportunities to practice needs identification skills, leaving our students unprepared to meet the societal challenges facing bioengineers.

2. Inherently interdisciplinary, bioengineering curricula are historically broad, sacrificing depth. Our curriculum is no exception, which struggles with the difficulty of simultaneously providing breadth and depth. Our students lack opportunities to develop deep technical expertise, ultimately threatening a core faculty value of developing deep technical competencies in our students.

3. By trying to provide both breadth and depth, we have created an inflexible curriculum that stifles creativity and passionate pursuits, keeping students and faculty from deeply engaging in undergraduate research, internships, study-abroad, or clinical experiences. As mentioned in the first threat, these types of experiences can be critical for providing students with opportunities to practice their need-identification skills.

4. Our campus has recently announced its plans to create a new engineering-based College of Medicine (CoM). This CoM will be a boutique medical school with a small class and the unique curriculum will be co-taught across disciplines through existing faculty on campus. Because of the integrated nature of engineering and medicine, many Department of Bioengineering faculty will play a central role in developing the curriculum and courses for this new CoM. This time spent could render our current model of instruction and teaching assignments unsustainable. Without change, our faculty will be overloaded with teaching responsibilities and students will receive less contact with faculty.

\section{Core objectives to address the key threats}

These threats provide external and internal pressures that necessitate change ${ }^{18-20}$. Our simple message encapsulates four objectives that will symbiotically support each other (Figure 1) and will drive discussions with faculty representatives. These objectives will create a transferable and scalable model for revolution in engineering education: a needs-driven engineering curriculum. Our objectives are

1. Integrate co-curricular clinical experiences into the undergraduate curriculum

2. Reorganize courses and faculty teaching efforts into needs-driven curriculum tracks

3. Translate medical assessment practices into engineering education contexts to unify the clinical experiences and curriculum tracks into a holistic curriculum

4. Organize faculty into communities of practice (CoPs) to provide faculty development

\section{Integrating co-curricular clinical experiences into the undergraduate curriculum}

Students as early as freshman year will be exposed to co-curricular and clinical experiences in BIOE120: Introduction to Bioengineering. In the 2015-2016 academic year, the course was restructured into three professional tracks: industry, clinical, and research. Lectures and immersive experiences were tailored for each track by the course instructors. For example, Prof. Jennifer Amos coordinated the clinical track in collaboration with Dr. John Vozenilek from OSF Hospital in Peoria. This track taught students ethnographic skills to help them identify high-impact 
problems. Students practiced these skills during three hours of shadowing volunteering each week at Carle Foundation Hospital. Students collected observational data to identify issues related to physical spaces, processes, safety, and devices or electronic medical records. They then applied these observations to the process of product design and development. Specifically, they focused on the formulation and evaluation of potential solutions to the challenges they observed.

Moving forward, we will form a clinical advisory group with physicians from Carle and OSF. They will lead seminar lectures defining clinical problems and needs in order to supplement our students' immersion experiences. Shadowing will additionally give our students the time and freedom learn about medical residents and interns' personal experiences first hand while also providing ample opportunities to discuss clinical needs.

Further, faculty working on medical school development will bring practices from medicine into bioengineering and from bioengineering into medicine, thereby benefitting both programs with time spent on development. An example of this is the use of case studies in both the engineering and medical curricula. Cases developed will be used in both settings to maximize efforts of time spent and further relate the two fields. The cases may be presented differently or have different goals, i.e. a computational model to predict efficiency of CPR for bioengineers versus a differential diagnosis of heart disease for the medical students, but the essence of the case will be the same. Additionally, having both groups with cases in common will help both sets of students have common ground for understanding during their immersion at the hospital.

\section{Reorganize courses and faculty teaching efforts around societal needs}

Our original undergraduate curriculum focused on five technical tracks: 1) biomechanics, 2) cell and tissue engineering, 3) therapeutics engineering, 4) computational and systems biology, and 5) imaging and sensing. To provide technical depth, we required students to continue in their technical tracks once they were selected.

To reimagine our curriculum, we have begun working with our faculty to identify how we might reorganize our curriculum around the diseases and health challenges that they are interested in solving with their research groups. During our annual faculty retreat, the faculty identified a set of possible challenges to address, and indicated their willingness to work within a community of practice to create learning experiences for students excited by those challenges. We created a survey from this list to gauge the faculty's interest in creating new learning communities focused on each of the different diseases and health challenges. These interests will determine will drive our formation of communities of practice. The results of this survey are presented in Table 2.

Table 2: List of health challenges and diseases that align with our faculty's research and career interests.

\begin{tabular}{|l|l|l|}
\hline Health Challenge/Disease & $\begin{array}{l}\text { Number of faculty who want to engage in a } \\
\text { community focused on the health challenge }\end{array}$ & $\begin{array}{l}\text { Percentage of } \\
\text { faculty }\end{array}$ \\
\hline Cancer/Cancer Technologies & 19 & $86 \%$ \\
\hline Neuro/Brian Pathologies & 16 & $73 \%$ \\
\hline Cardiovascular Diseases & 14 & $64 \%$ \\
\hline
\end{tabular}




\begin{tabular}{|l|l|l|}
\hline Personalized Medicine & 13 & $59 \%$ \\
\hline Infectious Diseases & 11 & $50 \%$ \\
\hline Aging & 9 & $41 \%$ \\
\hline Global Health/Global and Mobile & 8 & $36 \%$ \\
\hline Affordable Healthcare & 6 & $27 \%$ \\
\hline Sustainability & 3 & $14 \%$ \\
\hline
\end{tabular}

Discussions about the selection of these communities has revealed potentially two juxtaposed aspects of these health challenges: 1) biological diseases and health challenges and 2) the societal design constraints of the technologies needed to address those diseases. Cancer, neuro/brain, cardiovascular, infectious, and aging-related diseases all represent this first aspect while personalized medicine, global health, affordable healthcare, and sustainability represent this second aspect. When trying to develop technologies and treatments for cancer, for example, one could choose to either develop expensive but highly effective personalized treatment or to develop cheaper and more broadly accessible treatments that could be deployed in developing countries.

To illustrate how our faculty have begun to organize and create communities of practice around a disease, we briefly describe the creation of the cancer scholars program. The Cancer Scholars Program attempts to apply engineering practices to advancing cancer research. Cancer, which affects one out of every two Americans ${ }^{21}$, is a great societal problem, a complex scientific problem, and has tremendous implications if solved. Students who enter this program take the same courses other bioengineering students do, but with a focus on cancer. As freshmen, they take a new 1-hour course "Frontiers in Cancer Research" that presents an overview of the current challenges faced in cancer research. Students are also required to choose a research advisor their first semester, start laboratory work their spring semester, and participate in a summer "research bootcamp". They can choose electives throughout their sophomore and junior years like "Healthcare Innovation by Engineering" that deepen their understanding of healthcare technology, policy, and needs, and can participate in clinical or industry immersion experiences. These classes and experiences culminate in their capstone design project, which they plan in their junior year and complete in their senior year.

\section{Future Work}

Moving forward, we aim to come closer to solving the health challenges that will shape the tracks in our curriculum and implement these challenges into faculty-led communities of practice that are integrated into the project-based curriculum. The health challenges in these communities will be the point of integration for co-curricular, research, and core curricular projects, which will drive innovation in approaches to solving these health challenges. By involving the faculty and students in the process of identifying, choosing, and shaping the changes, we are creating an environment where change can be adopted and widely supported within the larger community. 


\section{References}

1 Grinter, L. E. Summary of the report on the evaluation of engineering education. J. Eng. Ed. 46, 25-60 (1955).

2 Froyd, J., Wankat, P. \& Smith, K. Five major shifts in 100 years of engineering education. Proceedings of the IEEE 100, 1344-1360 (2012).

3 Jamison, A., Kolmos, A. \& Holgaard, J. E. Hybrid learning: An integrative approach to engineering education. J. Eng. Ed. 103, 253-273 (2014).

4 Downey, G. in Cambridge Handbook of Engineering Education Research (ed Aditya Johri and Barbera Olds) Ch. 14, 693-711 (Cambridge University Press, 2014).

5 Goldberg, D. E. \& Sommerville, M. A Whole New Engineer. (ThreeJoy Associates, 2014).

6 Downey, G. in NSF Engineering Education Awardee's Meeting (Arlington, VA, 2014).

7 Trevelyan, J. Reconstructing engineering from practice. Engineering Studies 2, 175-195 (2010).

8 Trevelyan, J. The Making of An Expert Engineer. (Taylor and Francis, 2014).

9 Holdren, J. P. \& Lander, E. S. "Better Health Care and Lower Costs: Accelerating Improvement through Systems Engineering" Report to the President Better Health Care and Lower Costs: Accelerating Improvement through Systems Engineering. (Council of Advisors on Science and Technology, 2014).

10 Alpern, R. J. \& Long, S. Scientific Foundations for Future Physicians. (Association of American Medical Colleges/Howard Hughes Medical Institute, Washington, DC, 2009).

11 He, B. et al. Grand challenges in interfacing engineering with life sciences and medicine. IEEE Transactions on Biomedical Engineering (2013).

12 Petroski, H. Success Through Failure: The Paradox of Design. (Princeton University Press, 2013).

13 Petroski, H. The Essential Engineer: Why Science Alone Will Not Solve Our Global Problems. (Knopf, 2010).

14 Westwood, J. D. Medicine meets virtual reality 02/10: Digital Upgrades Applying Moore's Law to Health. Vol. 85 (IOS Press, 2002).

15 Blader, S. L. \& Tyler, T. R. Testing and extending the group engagement model: linkages between social identity, procedural justice, economic outcomes, and extrarole behavior. Journal of Applied Psychology 94, 445-464 (2009).

16 Colquitt, J. A. On the dimensionality of organizational justice: a construct validation of a measure. Journal of Applied Psychology 86, 386 (2001).

17 Beer, M. Leading Change. (Harvard Business School Teaching Note, 2007).

18 Kotter, J. P. Leading Change. (Harvard Business Review Press, 2012).

19 Beer, M. \& Nohria, N. Breaking the Code of Change. (Harvard Business Press, 2000).

20 Tushman, M. L. \& O'Reilly, C. A. Winning Through Innovation: A Practical Guide to Leading Organizational Change and Renewal. (Harvard Business Press, 2013).

21 Hayat, M. J., Howlader, N., Reichman, M. E. \& Edwards, B. K. Cancer statistics, trends, and multiple primary cancer analyses from the Surveillance, Epidemiology, and End Results (SEER) Program. The Oncologist 12, 20-37 (2007). 